\title{
Investigating the Determinants of Innovation According to Radical and Incremental Attributes
}

\author{
Chieh-Heng Ko \\ Department of Hospitality Management, College of Tourism and Hospitality, Da-Yeh University, Taiwan \\ Email: chko@mail.dyu.edu.tw
}

How to cite this paper: Ko, C.-H. (2017) Investigating the Determinants of Innovation According to Radical and Incremental Attributes. Open Access Library Journal, 4: e3994.

https://doi.org/10.4236/oalib.1103994

Received: September 30, 2017

Accepted: October 24, 2017

Published: October 27, 2017

Copyright (c) 2017 by author and Open Access Library Inc.

This work is licensed under the Creative Commons Attribution International License (CC BY 4.0).

http://creativecommons.org/licenses/by/4.0/ (c) (i) Open Access

\begin{abstract}
In today's competitive environment, firms cannot remain competitive without the implementation of proper innovations. There has been a dramatic proliferation of research concerned with firms' innovation, but few study has been done on determinants of innovation, particularly in hotel industry. Therefore, the aim of this study is to explore the main determinants of innovation applied in the hotel industry and investigate the influence of different hotels and market characteristics on radical and incremental innovations. A questionnaire was developed to investigate the abovementioned relationships. A total of 239 Taiwanese hotel employees participated in this study. Data were analyzed through probit model. The results indicated that radical and incremental innovations seem to be interrelated. In addition, the main determinants of innovation are the internal resources and market behaviours in the hotel trade that include management style, market strategy, hotel size and location.
\end{abstract}

\section{Subject Areas}

Business Analysis, Strategic Management

\section{Keywords}

Determinants of Innovation, Radical Innovation, Incremental Innovation, Hotel

\section{Introduction}

In today's business environment, an essential element to an organization's success is adaptability and the ability to manage the speed of change which in turn requires innovation [1]. Innovation and its support of innovation are vital for 
long-term corporate success. Firms that deliver the same products and services in the same way will not long survive, especially in the growing global economy, which continually emphasizes innovation. Therefore, executives responsible for hotel planning, operations and management must be more innovative and innovative than ever before. Previous research has examined the influence of organizational factors on individual innovation [2], environmental stimulants and obstacles to innovation [3] and work environment for innovation [4], but innovation has different type and the influence of different level of innovation should not be neglected. Therefore, we use two different types of innovation, radical and incremental, to examine the influence of different level of innovation on hotel industry and explore the relation between radical and incremental innovation.

\section{Literature Review}

\subsection{The Innovation Phenomenon}

According to Schumpeter, innovation is the creation of new possibilities for additional valued added, taking into account not only the typical product/process innovation of manufacturing but also market, organisational, and resource input innovation. As competition intensifies and the pace of change accelerates, firms need to exploit existing competences or exploring new opportunities [5]. The concept of exploration and exploitation in innovation emerged from Danneels [6], Lee et al. [7] and Rothaermel and Deeds [8] to investigate the capacity of firms to develop both types of innovation converting them in an ambidextrous organizations [9] [10]. There is little evidence of the study of exploratory and exploitative development. The majority of empirical analyses concentrate on the relation between radical and incremental innovation with mixed results [11]. Traditionally, the degree of radicalness has been determined by applying the criteria derived from a review of the relevant literature on this issue. The criterion set for radicalness by Ettlie et al. [12] is the magnitude of the cost of the change. They note that those innovations that incorporate a technology that represents a clear break from an existing practice (a new technology that requires changes in both procedures and products) will probably entail a significant cost that defines the innovation as radical rather than as incremental. Dewar and Dutton [13] distinguish innovations according to the degree to which they incorporate new knowledge in relation to their risk. They identify radical innovations as fundamental and revolutionary changes in the technology, involving new knowledge that breaks with existing practice and is positively related to the risk involved in attempting the innovation. Incremental changes are improvements in or adaptations of current technology that are less costly and have more predictable results. Likewise, they note that the requirements in knowledge resources will depend on the perception of those familiar with the innovation's degree of departure from the knowledge state prior to its introduction. In a study of the effects of organisational complexity on innovation, Damanpour [14] defines radical innovations 
as those that cause fundamental changes in the structure, procedures, and activities of the organisation; and that represent a large, clear break with existing practices. Incremental innovations, in contrast, cause a lesser break with the existing practices.

In this study, we measure radical innovation style as a clear break with existing practices or technologies and ones that are more likely than are incremental innovations to incorporate new knowledge. Radical innovations also tend to be riskier and more costly and would cause greater changes in the structure, procedures, products, or activities of the organisation. Radical innovations, understood to be applications of solutions for problems that are unsolved up to a given time, usually involve an elevated cost and have a great potential for impact on company profits. They are linked with the cumulative learning process. In contrast to a radical innovation, an incremental innovation usually involves less cost and less impact on company profit, regardless of the importance of the continual incremental innovation to the firm's competitiveness. Thus, incremental innovation represents the addition of services attributes to an existing service in the same sense that exploitation and exploration innovation in Danneels [6], Lee et al. [7], and Rothaermel and Deeds [8].

Therefore, in our context, we differentiate between radical and incremental innovation, using a dimension that denotes whether they were introduced for the first time (learned or explored) or consisted of modifications, improvements, or extensions to previously introduced innovations (additional or exploitative). In our scheme, the first time a firm includes or adopts an innovation, is a radical innovation; whereas modification to a previous innovation represents an incremental innovation.

\subsection{Innovation Degree}

Service is an important factor in the provision of hotels; and as for other service sectors, the introduction of technological assets is important in achieving service efficiency and improvements in service output. Therefore, innovation consists of the adoption of technological improvements in the areas, departments, and services that are key elements in provision of services [15]: control processes such as quality control and control of environmental management, computer equipment, information and telecommunications technologies, kitchens, food and beverage service, rooms, and maintenance and savings in utilities, security, and cleaning and laundry service. In these areas, the incorporation of technologies developed internally or sourced from commercial suppliers is apt to be translated into a competitive advantage, either because of productive efficiency (decreased costs) or because of increased service differentiation (improving the service provided by adapting it to consumer demand). Simultaneously, the innovations in these areas may be categorised as radical or incremental, according to whether they were introduced for the first time or consisted of modifications, improvements, or extensions to previously introduced innovations. The first-time inclusion or adoption of innovations that are internally developed or sourced 
from commercial suppliers incorporates all the dimensions relevant to radicalness; whereas such incremental innovations as improvements incorporate a lesser degree of radicalness.

Because radical innovation degree entails a learning process [2], it can be deduced that incremental innovation necessarily occurs after a radical innovation. Nevertheless, this sequential dependency does not exclude simultaneity, to the extent that all the resources and capacities developed for either of the two degrees will be of great value for the other degree [14]. The resources and capacities that are valuable in radical innovation, which are of higher cost and greater complexity, will also be valuable in incremental innovation. Similarly, the updating of resources and capacities associated with incremental innovation will allow for a more rapid accumulation and generation of more complex knowledge, resources, and capacities that are required for radical innovation [16]. Therefore, although the simultaneity of the two types of innovation could be restrained because of the limited resources available, we formulate the following hypotheses:

Hypothesis 1a. The hotel establishments that have introduced incremental innovation have a greater probability of innovating radically.

Hypothesis $1 \mathrm{~b}$. The hotel establishments that have introduced radical innovation have a greater probability of innovating incrementally.

\subsection{Ownership and Management}

The hotel may be managed by its owners or by another entity that acts as a contract manager for the owners (e.g. a rental contract or a management contract), involving different incentives and risks [17]. Some authors have suggested that the owner-manager form of structure could mean lesser resources, less specialisation in management, and less professional managers [17], all of which can negatively influence the innovative activity. However, it can be argued that the owner-manager structure can be a positive factor in innovation, considering the risks that are associated with the alternate form, a rental or management contract. For example, in order to acquire specialised management, owners must mediate a contract for the exploitation of the business and incur increased risks such as potential losses in the case of breach of contract or the greater costs associated with renegotiating the contract. It is expected, therefore, that at the time of mediating a management contract, decisions are made in favour of adopting innovations that are less risky-innovations for which short-term economic profitability is highly probable, or innovations that are required in order to stay in the market. In fact, it has been argued that the attitude of managers confronting the innovation change may determine the degree of radicalness of the innovations adopted [12] [13] [14] highlighted management attitudes as being important determinants of the development or acquisition of innovation by tourism business. Getz and Carlsen [17] concluded that owner-managed businesses are run by people with more entrepreneurial attitudes because the owners tend to control and monitor all stages of the decision making process. These argu- 
ments lead us to formulate the following hypothesis:

Hypothesis 2. When the hotel establishment is managed by the owners, there is a greater probability of engaging in radical innovations than in incremental innovations.

\subsection{Market Strategy}

A firm's strategic decision to differentiate itself from competitors will affect its productive resources, the services it offers, the organisation and management of its operations, and, therefore, its innovation decisions [18]. Therefore, innovative activity would be a consequence of the market strategy. A strategic decision to differentiate may give rise to the implementation of innovative measures. In particular, the decision to undertake radical innovation is more probable in establishments for which the differentiation strategy is based on the provision process, because it involves less client contact and greater capital intensity [14]. In contrast, a service differentiation strategy, which involves a greater presence of human resources, is less likely to involve radical innovation. Analogously, opting for incremental innovation is more probable in establishments in which the differentiation strategy is based on adjusting the service provided; the firm adapts itself to the demands of the clientele with the least possible risk.

Nevertheless, another important characteristic of hotel competition in the market is the seasonal demand faced by hotel firms [17]. This seasonal demand, combined with a structure of high fixed costs that increase the minimum occupancy level required to reach minimum acceptable profitability [19], make it more profitable for some establishments to close during periods of lesser tourist demand. Therefore, acquiring more information will create a greater understanding of the determinants of competitiveness, including innovation. This accumulation of knowledge resources will favour radical innovation [13]. Finally, during periods of lower occupancy, those establishments that remain open could make the most of operating at less than maximum capacity by introducing innovations that require more trials and adjustments [16] which, in turn, could foster the generation of new knowledge necessary for radical innovation [13]. Thus, regarding market factors and hotel behaviour in the market, we formulate the following hypotheses:

Hypothesis 3a. A market strategy based on differentiating the provision process will positively affect radical innovation to a greater extent than it affects incremental innovation.

Hypothesis 3b. A market strategy based on differentiating the service provided will positively affect incremental innovation to a greater extent than it affects radical innovation.

\section{Methodology}

\subsection{Data and Sample}

After an extensive literature review and a series of in-depth interviews with ex- 
pert panels, the questionnaire was developed by the researchers. Based on the comments collected during the pilot testing period, items that were not clearly stated were revised, and a complete questionnaire was developed. In carrying out innovation, the hotel trade does not designate significant resources for the generation of new knowledge, nor does it typically give rise to the registration of patents [15]. Thus, the information to detect innovation in the hotel trade necessarily comes from the primary information sources, that is, from the hotel companies. Therefore, relevant data must be collected by means of questionnaire survey specifically developed for the managers of the establishments. This research sample consisted of employees from 27 hotels in Taiwan. A total of 320 questionnaires were distributed, and $253(79.1 \%)$ questionnaires were received due to large portions of missing values. Finally, 239 (74.7\%) questionnaires were analyzed in this study.

\subsection{Variables}

The binary variable Management captures the organisational resource form used to manage the establishment. Management equals 1 if the owner managed the hotel business and 0 if the management contract or a rental contract for operating the hotel business is owned by another party. The strategic decision of differentiation for each establishment is measured by the binary variables Process and Service. Process takes the value 1 if the establishment reported that it differentiates in its provision process and 0 if it did not. Service takes the value 1 if the establishment reports that it differentiates on the basis of the service provided or on its presentation and 0 if it does not. The market-orientation strategy is approximated by the degree of use of assets labelled as the variable Market, a discrete variable that takes a value equal to the number of months per year that the particular hotel stays open.

\subsection{Analysis}

One probit model is estimated for radical innovation and another for incremental innovation, in order to determine if the determinants of the two degrees of innovation differ. The models for each innovation degree are estimated in two cases. In the first case, the estimations do not include the interdependency hypothesis with the aim of producing a model that can explain each innovation degree with only the explanatory variables. In the second case, for each of the innovation degrees, the other innovation degree is included as an independent variable in the form of instrumental variables. Including the incremental (or radical) innovation in the explanation of the radical (or incre-radical) innovation allows us to detect any interdependency that might exist between the two types of innovation. Given that nearly half of the sample's elements, have decided to innovate both radically and incrementally. In order to avoid unexpected problems derived from the similarity between the radical and incremental variables we use instrumental variables obtained by estimating the model in two 
steps. The first step consists in regress the INCREMENTAL and RADICAL variables on over all the explanatory variables and their interactions; then we obtain the predictions of both variables. In the second step, we introduce the new independent variables - predictions of INCREMENTAL and RADICAL-in the Models 3 and 4 .

\section{Results}

In Table 1 we display the means and standard deviations of the variables and the correlations among them. Onaverage, approximately $80 \%$ of hotels carry out incremental innovation whereas only $50 \%$ implement radical innovation. The majority of hotels use a management contract and this approach is mainly used to differentiate the service. The estimated probit models turn out to be useful in the explanation of radical and incremental innovation degrees because, for all models, the overall effect of the explanatory variables on the dependent variable is statistically significant. For each estimated model, the coefficients that are significantly non-zero indicate that the variable in question causes an increase (decrease) in the probability that the hotels innovate radically (Models 1 and 3) or incrementally (Models 2 and 4) (Table 2). Thus, we confirm H1a and H1b, and conclude that interdependency between the two types of innovation decisions exists; incremental (or radical) innovation degree increases the probability of also implementing radical (or incremental) innovation. In fact, the correlation between the values of the original variables, RADICAL and INCREMENTAL, is 0.34 and the p-value that rejects the null hypothesis of independence is smaller than 0.01 (see Table 1). Results also indicate that management by owner decreases the expected probability that a hotel establishment innovates either radically or incrementally. Thus we cannot confirm $\mathrm{H} 2$ in the sense it is proposed.

Among the market behaviour factors, the market orientation and a strategic decision of differentiation in the provision process are factors that increase the probability of having a radical innovation style. Nevertheless, we are prevented from concluding that there are also such factors in incremental innovation. Hence, $\mathrm{H} 3 \mathrm{a}$ and $\mathrm{H} 3 \mathrm{~b}$ are statistically robust.

Table 1. Descriptive and correlations.

\begin{tabular}{|c|c|c|c|c|c|c|c|c|}
\hline Variable & Mean & S.D & 1 & 2 & 3 & 4 & 5 & 6 \\
\hline 1. Radical & 0.5061 & 0.5006 & 1.0000 & & & & & \\
\hline 2. Incremental & 0.8431 & 0.3632 & $0.3869^{* * *}$ & 1.0000 & & & & \\
\hline 3. Management & 0.7182 & 0.4521 & $-0.1578^{\star * \star}$ & $-1.1563^{\star * *}$ & 1.0000 & & & \\
\hline 4. Process & 0.1296 & 0.3256 & $0.2178^{\star * *}$ & 0.0841 & $-0.1386^{* *}$ & 1.0000 & & \\
\hline 5. Service & 0.3832 & 0.4863 & $0.1312^{\star *}$ & $0.1531^{\star * *}$ & $-0.1266^{* *}$ & $0.1635^{\star * *}$ & 1.0000 & \\
\hline 6. Market & 8.2863 & 2.4138 & $0.1031^{\star}$ & 0.0621 & $-0.1212^{\star \star}$ & $0.1082^{\star \star}$ & $0.1031^{\star}$ & 1.0000 \\
\hline
\end{tabular}


Table 2. Results of the probit econometric estiations.

\begin{tabular}{|c|c|c|c|c|}
\hline \multirow{3}{*}{$\begin{array}{c}\text { Independent } \\
\text { variables }\end{array}$} & \multicolumn{2}{|c|}{ Estimations without interdependency } & \multicolumn{2}{|c|}{ Estimations with interdependency } \\
\hline & Model 1 & Model 2 & Model 3 & Model 4 \\
\hline & Radical & Incremental & Radical & Incremental \\
\hline \multirow[t]{2}{*}{ Management } & $-0.3786^{\star \star}$ & $-0.5331^{\star *}$ & $-0.3882^{* *}$ & $-0.5046^{\star *}$ \\
\hline & {$[0.1731]$} & {$[0.2521]$} & {$[0.1763]$} & {$[0.2573]$} \\
\hline \multicolumn{5}{|l|}{ Strategy in } \\
\hline \multirow[t]{2}{*}{ Process } & $0.4632^{*}$ & -0.1625 & $0.5233^{\star *}$ & -0.2463 \\
\hline & {$[0.2561]$} & {$[0.3668]$} & {$[0.2612]$} & [0.3751] \\
\hline \multirow[t]{2}{*}{ Service } & 0.0571 & 0.3156 & 0.0286 & 0.2931 \\
\hline & {$[0.1587]$} & {$[0.2071]$} & {$[0.1628]$} & {$[0.2114]$} \\
\hline \multirow[t]{2}{*}{ Market } & $0.0723^{* *}$ & 0.0451 & $0.0712^{\star *}$ & 0.0263 \\
\hline & {$[0.0326]$} & {$[0.0412]$} & {$[0.0331]$} & [0.0431] \\
\hline \multirow[t]{2}{*}{ Incrementalpred } & & & $1.2523^{* * *}$ & \\
\hline & & & {$[0.4462]$} & \\
\hline \multirow[t]{2}{*}{ Radicalpred } & & & & $0.4476^{*}$ \\
\hline & & & & {$[0.2634]$} \\
\hline LR & 62.83 & 44.73 & 72.52 & 47.71 \\
\hline Prob $>$ & 0.0000 & 0.0000 & 0.0000 & 0.0000 \\
\hline Pseudo & 0.1412 & 0.1624 & 0.1525 & 0.0000 \\
\hline$\%$ pred. corr. & 68.22 & 84.42 & 69.47 & 85.98 \\
\hline
\end{tabular}

The marginal effects indicate the influence of each innovation degree on the other: Establishments that innovate incrementally increase the expected probability of innovating radically by $41 \%$; whereas, if an establishment innovates radically, its expected probability of innovating incrementally increases by only $8.5 \%$. Regarding the management form, if management based on a contract with third parties is changed to management by the owner, the expected probability for radical innovation of that establishment decreases by $15 \%$, whereas the probability for incremental innovation decreases by $8 \%$.

\section{Discussion and Conclusions}

The results allow for empirical verification of the model. The hypothesis of simultaneous as opposed to sequential interdependency between the two degrees of innovation is supported empirically in both directions and with a different magnitude: The estimated effect of incremental innovation on radical innovation is almost five times greater than the estimated effect of radical innovation on incremental innovation. Although, by definition, incremental innovation occurs after some radical innovation, the greater effect of incremental innovation on radical innovation is not surprising, because we analysed for simultaneous 
interdependency. Therefore, it appears that the effect of incremental innovation is one that involves the generation, accumulation, and updating of resources and capacities for innovation [16]. The resources and capacities developed for radical innovation would have their greatest value in the subsequent incremental innovation and a lesser value for the simultaneous innovation, whereas the updating of resources and capacities for incremental innovation would foster the accumulation of the essentials for innovation more generically. It seems that the disentangling of service innovation in both degrees, as Gallouj and Weinstein [2] showed, is appropriate in our analysis.

Regarding the impact of the form of management of hotels, we have found that, contrary to $\mathrm{H} 2$, non-owner managers are more likely than are owner managers to undertake radical innovation. Thus, it appears that the increased risk for radical innovation that arises from the mediation of a hotel management contract is more than compensated for by the greater specialisation in management and a greater understanding of the determinants of hotel competition that accompany the use of specialised (non-owner) managers. Specialised management could also be positively related to a managerial attitude that is more inclined to fostering change [13] [14]. The non-confirmed influence of operating independently vs. being part of a hotel chain or business conglomerate can be explained by noting that the knowledge, information, and other intangibles provided by the chain or conglomerate [20] may be compensated for by the incentives derived from competition.

$\mathrm{H} 3 \mathrm{a}$ and $\mathrm{H} 3 \mathrm{~b}$, concerning the strategic differentiation in the provision process and in market orientation are verified empirically with regard to their influence on radical innovation. Therefore, it can be concluded that these market factors are determinants of innovation that differ according to their degree. Compared to the service differentiation strategy, differentiation in the provision process is a determinant in radical innovation, insofar as it involves less client contact and is more capital intensive [14]. The service differentiation strategy, on the other hand, involves greater presence of human resources. The failure to confirm an effect of the differentiation in the service provided could be because this style of differentiation can be achieved with small modifications that do not give rise to innovation. On the other hand, the establishments with a stronger market-orientation strategy implemented over time would be able to introduce innovations that require more trials and adjustments when they are functioning below maximum capacity [16], thereby generating more options for radical innovation.

Previous discussion has drawn conclusions about the internal resources and market behaviours in the hotel trade that serve to increase the probability of implementing radical innovation independent of incremental innovation. However, we are aware of some limitations in our empirical analysis, mainly related with the form in which we have measured the radicalness degree. Our measure could not detect all innovations or over evaluate some others; bearing in mind this drawback, we can conclude that third-party management affects radical in- 
novation to a greater extent than it affects incremental innovation. The implementation of incremental innovation, a differentiation in the provision process, a greater market orientation positively affect radical innovation. On the other hand, incremental innovation is positively influenced by radical innovation and by recourse to tour operators.

\section{References}

[1] Huybers, T. and Bennett, J. (2000) Impact of the Environment on Holiday Destination Choices of Prospective UK Tourists: Implications for Tropical North Queensland. Tourism Economics, 6, 21-46. https://doi.org/10.5367/000000000101297451

[2] Gallouj, F. and Weinstein, O. (1997) Innovation in Services. Research Policy, 26, 537-556. https://doi.org/10.1016/S0048-7333(97)00030-9

[3] Amis, J. and Slack, T. (2004) The Pace, Sequence and Linearity of Radical Change. Academy of Management Journal, 47, 15-39. https://doi.org/10.2307/20159558

[4] Drejer, I. (2004) Identifying Innovation in Surveys of Services: A Schumpeterian Perspective. Research Policy, 33, 551-562.

https://doi.org/10.1016/j.respol.2003.07.004

[5] Jansen, J.J.P., Van den Bosch, F.A.J. and Volberda, H.W. (2006) Exploratory Innovation, Exploitative Innovation, and Performance: Effects of Organizational Antecedents and Environmental Moderators. Management Science, 52, 1661-1674. https://doi.org/10.1287/mnsc. 1060.0576

[6] Danneels, E. (2002) The Dynamics of Product Innovation and Firm Competences. Strategic Management Journal, 23, 1095-1121. https://doi.org/10.1002/smj.275

[7] Lee, J., Lee, J. and Lee, H. (2003) Exploration and Exploitation in the Presence of Network Externalities. Management Science, 49, 553-570.

https://doi.org/10.1287/mnsc.49.4.553.14417

[8] Rothaermel, F.T. and Deeds, D.L. (2004) Exploration and Exploitation Alliances in Biotechnology: A System of New Product Development. Strategic Management Journal, 25, 201-221. https://doi.org/10.1002/smj.376

[9] Gibson, C.B. and Birkinshaw, J. (2004) The Antecedents, Consequences, and Mediating Role of Organizational Ambidexterity. Academy of Management Journal, 47, 209-226. https://doi.org/10.2307/20159573

[10] He, Z. and Wong, P. (2004) Exploration and Exploitation: An Empirical Test of the Ambidexterity Hypothesis. Organization Science, 15, 481-494.

https://doi.org/10.1287/orsc. 1040.0078

[11] Cardinal, L.B. (2001) Technological Innovation in the Pharmaceutical Industry: The Use of Organization Control in Managing Research and Development. Organizational Science, 12, 19-36. https://doi.org/10.1287/orsc.12.1.19.10119

[12] Ettlie, J.E., Bridges, W.P. and O'Keefe, R.D. (1984) Organization Strategy and Structural Differences for Radical vs. Incremental Innovation. Management Science, 30, 682-695. https://doi.org/10.1287/mnsc.30.6.682

[13] Dewar, R.D. and Dutton, J.E. (1986) The Adoption of Radical and Incremental Innovations: An Empirical Analysis. Management Science, 32, 1422-1433. https://doi.org/10.1287/mnsc.32.11.1422

[14] Damanpour, F. (1996) Organizational Complexity and Innovation: Developing and Testing Multiple Contingency Models. Management Science, 42, 693-716. https://doi.org/10.1287/mnsc.42.5.693 
[15] Hjalager, A.M. (2002) Repairing Innovation Defectiveness in Tourism. Tourism Management, 23, 465-474.

[16] Sirilli, G. and Evangelista, R. (1998) Technological Innovation in Services and Manufacturing: Results from Italian Surveys. Research Policy, 27, 881-899.

[17] Getz, D. and Carlsen, J. (2005) Family Business in Tourism. State of the Art. Annals of Tourism Research, 32, 237-258.

[18] Sundbo, J. (1997) Management of Innovation in Services. Service Industries Journal, 17, 432-455. https://doi.org/10.1080/02642069700000028

[19] Tisdell, C. (2000) The Economics of Tourism. Edward Elgar Publishing Limited.

[20] Ingram, P. and Baum, J. (1997) Chain Affiliation and the Failure of Manhattan Hotels, 1898-1980. Administrative Science Quarterly, 42, 68-102.

https://doi.org/10.2307/2393809

Open Access Library

Submit or recommend next manuscript to OALib Journal and we will provide best service for you:

- Publication frequency: Monthly

- 9 subject areas of science, technology and medicine

- Fair and rigorous peer-review system

- Fast publication process

- Article promotion in various social networking sites (LinkedIn, Facebook, Twitter, etc.)

- Maximum dissemination of your research work

Submit Your Paper Online: Click Here to Submit

Or Contact service@oalib.com 